\title{
MENGUJI KESYARIAHAN AKAD WADIAH PADA PRODUK BANK SYARIAH
}

Oleh : Bambang Murdadi, SE, MM

e-mail : bambangmurdadi@yahoo.co.id

\section{RINGKASAN EKSEKUTIF}

Salah satu akad dalam produk Perbankan Syariah adalah akad Wadiah. Pengertian Akad Wadiah adalah perjanjian penitipan dana antara pemilik dana dengan pihak penerima titipan yang dipercaya untuk menjaga dana tersebut; (PBI No.2/9/2000). Produk Perbankan Syariah dengan akad Wadiah antara lain dalam produk Giro Wadiah, Tabungan Wadiah, Sertifikat Wadiah Bank Indonesia. Sesuai dengan Fatwa dari Dewan Syariah Nasional bahwa produk giro wadiah secara umum memiliki kriteria 1. Bersifat titipan 2. Titipan bisa diambil kapan saja (on call) 3.Tidak ada imbalan yang disyaratkan, kecuali dalam bentuk pemberian (athaya) yang bersifat sukarela dari pihak bank. Adapun dasar syariahnya antara lain dalam Firman Allah QS Annnisa (4):29. Hai orang yang beriman! janganlah kalian saling memakan (mengambil) harta sesamamu dengan jalan yang batil, kecuali dengan jalan perniagaan yang berlaku dengan sukarela diantaramu. Di dalam praktek perbankan di lapangan, beleid (point) yang menyatakan "tidak ada imbalan yang dipersyaratkan" ataupun tidak ada imbalan yang dijanjikan dimuka apakah benar-benar telah diterapkan secara murni dan syar'ie?Perlu dikaji lebih mendalam. Baik tinjauan dari sisi legal formal (ketentuan yang ada) diluar fatwa Dewan Syariah Nasional maupun dalam praktek bisnis perbankan di lapangan. Dari hasil pengamatan dan diskusi, terkesan masih bersifat ambigu (abu-abu) ditengah praktek dunia bisnis perbankan yang penuh dengan persaingan yang sangat ketat.

Kata kunci : akad wadiah, titipan, imbalan sukarela. 


\section{PENDAHULUAN}

Perbankan syariah di Indonesia berkembang cukup pesat tercermin dari pangsa aset perbankan syariah dibandingan dengan perbankan konvensional saat ini mencapai sekitar 3\%. Produkproduk yang ditawarkan antara lain dalam penghimpunan dana dalam bentuk : giro (wadiah dan mudharabah) tabungan dan deposito mudharbah. Perbankan syariah yang berkembang baik di Indonesia maupun di bebarapa negara misalnya Malaysia, tidak dipungkiri pada awalnya lahir tidak Sharia Full totally applied (secara total langsung menerapkan syariah Islam), namun secara bertahap. Bank syariah banyak lahir melalui anak perusahaan bank atau window (bagian usaha bank) contohnya dalam bentuk Unit Usaha Syariah ataupun dengan mengkonversi (mengubah dari bank konvensional menjadi bank syariah( Syafei, Antonio,1999 :279) artinya praktek bank syariah yang masih menempel pada induknya yang merupakan bank konvensional. Dapat dikatakan bahwa modal bank syariah tersebut pada awalnya (dananya) berasal dari praktek bank konvensional (bank dengan berbasis bunga). Sampai saat inipun pola bank syariah dengan bentuk usaha seperti itu masih banyak, artinya bank syariah yang belum sepenuhnya syariah kalau memang menghendaki syariah murni modal berasal bukan dari bank konvensional yang berbasis bunga. Bukan hanya pada permodalan awal yang faktanya masih belum syariah, namun bisa saja pada produk-produk yang ditawarkan masih terdapat unsur-unsur yang belum "pure" syariah. Sekalipun hal ini tergantung pada pengelolanya sejauh mana memiliki komitmen kuat dan niat yang tulus untuk mewujudkan bank dengan produk murn syariah, baik dalam undangundang/ketentuan yang syar'ie (berdasarkan syariah) maupun dalam aplikasinya di lapangan. Salah satu produk yang memerlukan penelitian dan pendalaman yang tepat adalah produk-produk yang dikemas dalam akad wadiah. Produk perbaankan yang diikat dengan akad wadiah diantaranya adalah giro wadiah. Selain giro wadiah, akad wadiah juga diterapkan untuk produk infak, sodaqoh atau zakat. Sesuai dengan fatwa DSN, akad wadiah umum harus memiliki kriteria : 1. Bersifat titipan 2. Titipan bisa diambil kapan saja (on call) 3.Tidak ada imbalan yang disyaratkan, kecuali dalam bentuk pemberian (athaya) yang bersifat sukarela dari pihak bank. Dengan batas dan kriteria seperti itu, apakah memang bank-bank menerapkan dengan konsekwen, tidak ada janji dimuka bahwa bank tidak akan memberikan imbalan atau bonus. Dihadapkan pada kenyataan bahwa dunia bisnis perbankan adalah dunia yang penuh dengan persaingan yang ketat dalam merebut nasabah. Kalau diterapkan kepada prouk tertentu misalnya zakat infaq dan shdaqoh mungkin bisa saja karena memang dana terseut sudah diikhlaskan untuk keperluan tersebut, namun untuk produk lain seperti giro, apakah memang dapat diterapkan secara murni dan kosekwean. Contoh produk giro wadiah misalnya dalam bentuk Sertifikat Wadiah Bank Indonesia (SWBI). Selaipun produk tersebut juga sudah diatur dalam ketentuan Bank Indonesia dan tentu sudah mengacu pada fatwa dari DSN, siapa tahu dalam aplikasi masih terdapat sedikit unsur yang menyerempet kepada hal-hal yang belum syar'ie, sesuai dengan kaidah syariah Islam. Demikian pula produk dengan akad wadiah di bank-bak umum syariah pelaksana/bank komersial. Untuk itulah perlu adanya pengkajian yang terus menerus sehingga dapat dipastikan bahwa produk bank syariah yang diikat dalam akad wadiah yang sepenuhunya ,mengacu pada syariah sebagaimana dikehendaki sesuai dengan tuntuan syariah.

\section{DASAR-DASAR HUKUM SYARIAH PRODUK DENGAN AKAD WADIAH}


Dalam perekonomian dan Perbankan Islam, transaksi yang dilarang adalah transaksitransaksi yang mengandung riba (tambahan), maisyir (spekulasi) dan ghoror (tidak jelas)(Lasmiatun, 2010:103). Di dunia perbankan segala transaksi lazim dilandasi dengan akad. Adapun arti akad atau al-'aqdu adalah perjanjian, perikatan,permufakatan (Daeng Naja, 2011:17). Tentang perjanjian ini, Alloh swt berfirman dalam surat Al-Nahl ayat 91, yang artinya :" Dan tepatlah janji dengan Alloh apabila kamu berjanji dan janganlah kamu melanggar sumpah setelah diikrarkan, sedang kamu telah menjadikan Alloh sebagai saksimu (terhadap sumpah itu). Sesungguhnya Alloh mengetahui apa yang kamu perbuat". Dalam surat Al-Isra ayat 34 :" ...dan penuhilah janji karena janji itu pasti diminta pertanggungjawaban”. Sementara arti wadiah adalah titipan. Dalam konteks wadiah, barang yang dititipkan hanyalah sebatas titipan, tidak dibolehkan adanya tambahan ketika dikembalikan kepada sipenitipnya. Uang yang dititipkankan oleh nasabah, bank dapat mengoperasikan sejumlah tertentu, seraya bankpun dapat mengembalikan uang titipan ini pada saat penitipnya meminta kembali (Abu Sura'i, 1993:95). Atas definisi secara umum tersebut Dewan Syariah Nasional (DSN) mengeluarkan fatwanya terkait produk wadiah tersebut dengan konsideran sebagai berikut $\therefore$

a. Bahwa keperluan masyarakat dalam peningkatan kesejahteraan dan dalam bidang investasi, pada masa kini, memerlukan jasa perbankan; dan salah satu produk perbankan di bidang penghimpunan dana dari masyarakat adalah giro, yaitu simpanan dana yang penarikannya dapat dilakukan setiap saat dengan penggunaan cek, bilyet giro, sarana perintah pembayaran lainnya, atau dengan pemindahbukuan; b. Bahwa kegiatan giro tidak semuanya dapat dibenarkan oleh hukum Islam (syariah)

c. Bahwa oleh karena itu, Dewan Syariah Nasional (DSN) memandang perlu menetapkan fatwa tentang bentuk-bentuk muamalah syariah untuk dijadikan pedoman dalam pelaksanaan giro pada bank syariah.

Konsideran tersebut dengan mengacu pada hukumhukum syariah berikut :

1. Firman Allah QS Annnisa (4):29 Hai orang yang beriman ! janganlah kalian saling memakan (mengambil) harta sesamamu dengan jalan yang batil, kecuali dengan jalan perniagaan yang berlaku dengan sukarela diantaramu ..

2. Firman Allah QS Albaqarah (2):283, Maka, jika sebagian kamu mempercayai sebagian yang lain, hendaklah yang dipercayai itu menunaikan amanatnya dan hendaklah ia bertakwa kepada Allah Tuhannya

3. Firman Allah QS Almaidah (5):1 Hai orangorang yang beriman! penuhilah akad-akad itu

4. Firman QS Almaidah (5):2 Dan tolongmenolonglah dalam (mengerjakan) kebajikan ..

5. Hadis nabi riwayat al ThabraniAbbas bin Abdul Muthalib jika menyerahkan harta sebagai mudharabah. Ia mensyaratkan kepada mudharibnya agar tidak mengarungi lautan dan tidak menuruni lembah, serta tidak membeli hewan ternak, jika persyaratan itu dilanggar, ia (mudharib) harus menanggung resikonya. Ketika persyaratan yang ditetapkan Abbas itu didengar Rasulullah, beliau membenarkannya..(HR Thabrani dari Ibnu Abbas)

6. Nabi bersabda " ada tiga hal yang mengandung berkah : jual beli tidak secara tunai, muqaradah (mudharabah), dan mencampur gandum dan jewawut untuk kepentingan rumah tangga, 
bukan untuk dijual" (HR Ibnu Majah dari

Shuhaib)

7. Hadis Nabi riwayat Tirmidzi dari Amr bin Auf Perdamaian dapat dilakukan diantara kaum muslimin, kecuali perdamaian yang mengharamkan yang halal atau menghalalkan yang haram; dan kaum muslimin terikat dengan syarat-syarat mereka kecuali syarat yang mengharamkan yang yang halal atau menghalalkan yang haram.

8. Ijma. Diriwayatkan, sejumlah sahabat menyerahkan (kepada orang, mudharid) harta anak yatim sebagai mudharabah dan tak ada seorangpun mengingkari mereka. Karenanya, hal itu dipandang sebagai ijma' (Zuhaily, AlFiqh Alislami wa Adilatuhu, 1989, 4/838)

9. Qiyas. Transaksi mudharabah, yakni peyerahan sejumlah harta (dana, modal) dari satu pihak (malik, shahib al-mal) kepada pihak lain (amil, mudharib) untuk diperniagakan (diproduktifkan) dan keuntungan dibagi diantara mereka sesuai kesepakatan, diqiyaskan kepada transaksi musaqah.

10. Kaidah fiqh "Pada dasarnya, semua bentuk muamalah boleh dilakukan kecuali ada dalil yang mengharamkannya"

11. Para ulama menyatakan, dalam kenyataan banyak orang yang mempunyai harta namun tidak mempunyai kepandaian dalam usaha memproduktifkannya, sementara itu tidak sedikit pula orang yang tidak memiliki harta namun ia memiliki kemampuan dalam memproduktifkannya. Oleh karena itu, diperlukan adanya kerjasama diantara kedua pihak tersebut.

Menetapkan fatwa tentang GIRO

Pertama

1. Giro yang tidak dibenarkan secara syariah, yaitu giro yang berdasarkan perhitungan bunga
2. Giro yang dibenarkan secara syariah, yaitu giro yang berdasarkan prinsip mudharabah dan wadiah

Kedua : Ketentuan Umum Giro berdasarkan Mudharabah :

1. Dalam transaksi ini nasabah bertindak sebagai shahibul maal atau pemilik dana, dan bank bertindak sebagai mudharib atau pengelola dana.

2. Dalam kapasitasnya sebagai mudharib, bank dapat melakukan berbagai macam usaha yang tidak bertentangan dengan prinsip syariah dan mengembangkannya, termasuk didalamnya mudharabah dengan pihak lain.

3. Modal harus dinyatakan dengan jumlahnya, dalam bentuk tunai dan bukan piutang

4. Pembagian keuntungan harus dinyatakan dalam bentuk nisbah dan dituangkan dalam akad pembukaan rekening

5. Bank sebagai mudharib menutup biaya operasional giro dengan menggunakan nisbah keuntungan yang menjadi haknya.

6. Bank tidak diperkenankan mengurangi nisbah keuntungan nasabah tanpa persetujuan yang bersangkutan.

Ketiga : Ketentuan umum giro berdasarkan wadiah

1. Bersifat titipan

2. Titipan bisa diambil kapan saja (on call)

3. Tidak ada imbalan yang disyaratkan, kecuali dalam bentuk pemberian (athaya) yang bersifat sukarela dari pihak bank.

\section{PRODUK-PRODUK PERBANKAN SYARIAH DENGAN AKAD WADIAH}

Akad wadiah merupakan salah satu akad yang digunakan dalam kegiatan penghimpunan dana pada perbankan syariah. Sesuai dengan buku kodifikasi produk perbankan syariah yang dikeluarkan Bank Indonesia (2008). Ditetapkan definisi mengenai berbagai produk yang diterapkan 
di Bank Umum Syariah dan Unit Usaha Syariah (UUS), antara lain :

1. GIRO SYARIAH

Pengertian :

Giro adalah simpanan yang penarikannya dapat dilakukan setiap saat dengan menggunakan chek /bilyet giro dan sarana perintah pembayaran lainnya, atau dengan pemindahbukuan. Sedangkan akad wadiah adalah Transaksi penitipan dana atau barang dari pemilik kepada penyimpan dana atau barang dengan kewajiban bagi yang menyimpan untuk mengembalikan dana atau barang sewaktu-waktu

Fitur dan mekanisme : Giro atas dasar akad wadiah

> Bank bertindak sebagai penerima dana titipan dan nasabah bertindak sebagai penitip dana

Bank tidak diperkenankan menjanjikan pemberian imbalan atau bonus kepada nasabah

Bank dapat membebankan kepada nasabah biaya administrasi berupa biaya-biaya yang trkait langsung dengan biaya pengelolaan rekening antara lain biaya chek/bilyet giro, biaya meterai, cetak laporan transaksi dan saldorekening, pembukaan dan penutupan rekening

Bank menjamin dana titipan nasabah

$>$ Dana dapat diambil setiap saat oleh nasabah

Tujuan dan Manfaat

\section{BAGI BANK}

$>$ Sumber pendanaan, baik Rupiah maupun Valuta Asing

$>$ Salah satu sumber pendapatan dala bentuk jasa (fee base income) dari aktifitas lanjutan pemanfaatan rekening giro oleh nasabah

\section{BAGI NASABAH}

> Memperlancar aktivitas pembayaran dan/atau penerimaan dana

$>$ Dapat memperoleh bonus

\section{ANALISIS DAN IDENTIFIKASI RISIKO}

> Risiko likuiditas yang disebabkan oleh fluktuasi dana yang ada di rekening giro (wadiah) dan bank setiap saat harus memenuhi kewajiban jangka pendek tersebut

$>$ Risiko pasar yang disebabkan oleh pergerakan nilai tukar untuk giro (wadiah) dalam valuta asing

\section{FATWA SYARIAH}

$>$ Fatwa Dewan Syariah Nasional No 01/DSN-MUI/IV/2000 tentang Giro

\section{REFERENSI}

$>$ PBI No.3/10/PBI/2001 tentan Prinsip Mengenal Nasabah (KYC)

$>$ PBI No. 7/6/PBI/2005 tentang Transparansi Informasi Produk Bank dan Penggunaan Data Pribadi Nasabah

> PBI No.9/19/PBI/2007 tentang Pelaksanaan Prinsip Syariah Dalam Penghimpunan Dana dan Penyaluran Dana serta Pelayanan Jasa Bank Syariah.

\section{PERLAKUAN AKUNTANSI}

$>$ PSAK 59 tentang Akuntansi Perbankan Syariah

$>\quad$ PAPSI yang berlaku

\section{TABUNGAN WADIAH}

\section{Pengertian/Definisi}

Tabungan adalah simpanan yang penarikannya hanya dapat dilakukan dengan syarat tertentu 
yang disepakati, tetapi tidak dapat ditarik dengan chek atau bilyet giro dan/atau alat lainnya yang dipersamakan dengan itu

\section{AKAD TABUNGAN WADIAH}

Sedangkan akad tabungan wadiah adalah Transaksi penitipan dana atau barang dari pemilik kepada penyimpan dana atau barang dengan kewajiban bagi yang menyimpan untuk mengembalikan dana atau barang sewaktuwaktu

Fitur dan mekanisme : Giro atas dasar akad wadiah

$>$ Bank bertindak sebagai penerima dana titipan dan nasabah bertindak sebagai penitip dana

> Bank tidak diperkenankan menjanjikan pemberian imbalan atau bonus kepada nasabah

> Bank dapat membebankan kepada nasabah biaya administrasi berupa biaya-biaya yang trkait langsung dengan biaya pengelolaan rekening antara lain biaya chek/bilyet giro, biaya meterai, cetak laporan transaksi dan saldorekening, pembukaan dan penutupan rekening

> Bank menjamin dana titipan nasabah

$>$ Dana dapat diambil setiap saat oleh nasabah

Tujuan dan Manfaat

\section{BAGI BANK}

$>$ Sumber pendanaan, baik Rupiah maupun Valuta Asing

$>$ Salah satu sumber pendapatan dala bentuk jasa (fee base income) dari aktifitas lanjutan pemanfaatan rekening giro oleh nasabah

\section{BAGI NASABAH}

$>$ Kemudahan dalam pengelolaan likuiditas, baik dalam hal penyetoran, penarikan, transfer, dan pembayaran transaksi yang fleksibel

$>$ Dapat memperoleh bonus

\section{ANALISIS DAN IDENTIFIKASI RISIKO}

> Risiko likuiditas yang disebabkan oleh fluktuasi dana yang ada di rekening tabungan relatif tinggi dibandingkan dengan deposito

$>$ Risiko displacement (commercial displacement risk) yang disebabkan oleh adanya potensi nasabah memindahlan dananya yang didorong oleh tingkat bonus atau bagi hasil riil yang lebih rendah dibandingkan dengan tingkat suku bunga

$>$ Risiko pasar yang disebabkan oleh pergerakan nilai tukar untuk tabungan dalam valuta asing

\section{FATWA SYARIAH}

$>$ Fatwa Dewan Syariah Nasional No 02/DSN-MUI/IV/2000 tentang Tabungan

\section{REFERENSI}

$>$ PBI No.3/10/PBI/2001 tentan Prinsip Mengenal Nasabah (KYC)

$>$ PBI No. 7/6/PBI/2005 tentang Transparansi Informasi Produk Bank dan Penggunaan Data Pribadi Nasabah

$>$ PBI No.9/19/PBI/2007 tentang Pelaksanaan Prinsip Syariah Dalam Penghimpunan Dana dan Penyaluran Dana serta Pelayanan Jasa Bank Syariah.

\section{PERLAKUAN AKUNTANSI}

PSAK 59 tentang Akuntansi Perbankan Syariah 
PAPSI yang berlaku

\section{SERTIFIKAT WADIAH BANK NDONESIA} (SWBI)

Sertifikat Wadiah Bank Indonesia diterbitkan pada tahun 2000, nampkanya sebagai bentuk perkembangan produk perbankan syariah menjawab tantangan jaman sejalan dengan perkembangan dan pertumbuhan perbankan perbankan syariah itu sendiri. Diterbitkan sebelum UU No 24 tahun 2008 tentang perbankan syariah diundangkan, membuktikan adanya tuntutunan perkembangan produk dan secara luas bagi perekonomian adalah sebagai wujud dari tuntutan sarana/perangkat pengendalian moneter dari sisi kegiatan produk perbaankan syariah. Apabila di perbankan konvensional (bank dengan basis produk bunga) produk semacam SWBI adalah Sertifikat Bank Indonesia (SBI). SBI merupakan perangkat utama Bank Indonesia dalam pengendalian moneter dalam operasi pasar terbuka (OPT) dengan instrumen suku bunga SBI (BI rate), saat ini sebesar 7,50\% (Maret 2015:pen). Sebagai perangkat moneter utama dari sisi perbankan konvensional. Maka diciptakan perangkat semacam SBI untuk perbankan syariah dengan produk/sarana yang tentunya mengacu pada produk yang sesuai dengan syariah. Sebetulnya SWBI bisa menjadi perangkat moneter yang sangat efektif ketika perekonomian sedang menghadapi krisis karena "secara teori" SWBI bisa untuk mengenalikan uang uang beredar (sebagai perangkat untuk mengurangi dan menambah jumlah uang beredar (dala arti luas), namun mengingat daya tariknya adalah "bonus suka rela" apakah akan efektif melawan persaingan bisnis yang fully oriented to profit, jika dihadapkan pada SBI yang notebene beroperasi berbasis turun naiknya $\mathrm{BI}$ rate. Apalagi pangsa SWBI saat ini tentu masih kecil, mengingat pangsa aset perbankan syariah juga masih kecil sekitar $3 \%$.
Namun bisa saja kedepan bisa menjanjikan apabila masyarakat sudah syariah minded.

Dalam Peraturan Bank Indonesia No. 2/9/PBI/2000 tentang Sertifikat Wadiah Bank Indonesia yang menetapkan bahwa Wadiah adalah perjanjian penitipan dana antara pemilik dana dengan pihak penerima titipan yang dipercaya untuk menjaga dana tersebut. Dijelaskan bahwa Sertifikat Wadiah Bank Indonesia (SWBI) adalah sertifikat yang diterbitkan Bank Indonesia sebagai bukti penitipan dana berjangka pendek dengan prinsip Wadiah.

Adapaun karakteristik, jumlah dan jangka waktu penitipan dana diatur sebagai berikut :

1 Bank Indonesia dapat menerima penitipan dana dari Bank atau UUS dengan menggunakan prinsip Wadiah.

2 Sebagai bukti penitipan dana sebagaimana dimaksud dalam ayat (1), Bank Indonesia menerbitkan Sertifikat Wadiah Bank Indonesia (SWBI).

3 Bank Indonesia dapat memberikan bonus atas penitipan dana sebagaimana dimaksud dalam ayat (1) yang diperhitungkan pada saat jatuh waktu.

(1) Jumlah dana yang dapat dititipkan sebagaimana dimaksud dalam Pasal 2 ayat (1) sekurang-kurangnya Rp 500.000.000,00 (lima ratus juta rupiah).

(2) Penitipan dana di atas Rp 500.000.000,00 ( lima ratus juta rupiah) hanya dapat dilakukan dalam kelipatan Rp 50.000.000,00 (lima puluh juta rupiah).

Adapun jangka waktu penitipan dana ditetapkan 1 (satu) minggu, 2 (dua) minggu, dan 1

(satu) bulan yang dinyatakan dalam hari. Perubahan jangka waktu penitipan dana ditetapkan dengan Surat Edaran Bank Indonesia. 
TATA CARA PENYELESAIAN JATUH WAKTU PENITIPAN DANA

(1) Pada saat jatuh waktu penitipan dana, Bank Indonesia akan mengkredit rekening giro Bank atau UUS pada Bank Indonesia sebesar nilai titipan dana.

(2) Dalam hal Bank Indonesia memberikan bonus kepada Bank atau UUS pada saat jatuh waktu penitipan dana sebagaimana dimaksud dalam Pasal 2 ayat (3), maka Bank Indonesia akan mengkredit rekening giro bank sebesar nilai bonus yang besarnya diatur dalam ayat (3) dan ayat (4).

(3) Dalam hal Bank Indonesia akan memberikan bonus kepada Bank atau UUS yang menitipkan dana, maka besarnya bonus akan dihitung dengan menggunakan acuan tingkat indikasi imbalan Pasar Uang Antarbank berdas arkan prinsip Syariah (PUAS) yang merupakan rata -rata tertimbang tingkat indikasi imbalan Sertifikat Investasi Mudharabah Antarbank (Sertifikat IMA) yang terjadi di PUAS, pada tanggal penitipan dana.

(4) Dalam hal data mengenai tingkat indikasi imbalan PUAS sebagaimana dimaksud dalam ayat (3) tidak tersedia pada hari penitipan dana, maka besarnya bonus akan dihitung dengan menggunakan acuan tingkat indikasi imbalan PUAS terakhir yang terjadi atau rata -rata tingkat imbalan deposito investasi Mudharabah sebelumdidistribusikan pada bulan sebelumnya dari seluruh Bank yang melakukan kegiatan usaha berdasarkan prinsip syariah dan UUS.

\section{PANDANGAN KRITIS (CRITCAL POINT) KESYARIAHAN PRODUK DENGAN AKAD WADIAH}

Sekalipun semua produk perbankan syariah tentu sudah melalui Fatwa Dewan Syariah
Nasional, namun tidak berlebihan apabila proses di lapangan, dalam praktek perbankan baik dari asepek ketentuan yang dibuat oleh otoritas, pelaku usaha (perbankan) maupun praktek di lapangan dalam bentuk penerapan praktis akan selalu dikritisi, diperhatikan sehingga komitmen tentang kesyariahan dalam produk akan tetap terjaga.

Atas dasar kebijakan/ketentuan yang ada dan berdasarkan atas diskusi dengan para praktisi perbankan dapat dimunculkan hal-hal yang perlu dipertanyakan, dikritisi sebagaimana pandangan tentang produk-produk wadiah di bawah ini.

1. Giro Wadiah di Bank Umum

Giro adalah simpanan yang penarikannya dapat dilakukan setiap saat dengan menggunakan chek /bilyet giro dan sarana perintah pembayaran lainnya, atau dengan pemindahbukuan. Sedangkan akad wadiah adalah Transaksi penitipan dana atau barang dari pemilik kepada penyimpan dana atau barang dengan kewajiban bagi yang menyimpan untuk mengembalikan dana atau barang sewaktu-wakt

Produk titipan tersebut jangan sampai terjadi semacam janji tentang pemberian bonus di awal, sekalipun secara tertulis tidak ada, secara lisanpun tidak diperkenankan. Namun dalam suatu forum diskusi dengan praktisi perbankan. Seandainya si mudi"(penitip dana) sama sekali tidak diinformasikan tentang bonus yang akan diterima misalnya bonus setara nisbah bagi hasil sekian rupiah, maka dalam praktek bisnis riil yang dalam kenyataannya mengahadapi persaingan yang ketat, maka akan sulit bagi bank untuk dapat menghimpun dana dalam bentuk giro wadiah tersebut. Dalam kenyataan produk giro wadiah meliputi lalu-lintas dana dalam jumlah besar, karena sifatnya yang likuid (mudah untuk perputaran dana). Bagi dunia usaha, akan sulit apabila dana yang cukup 
besar tersebut ditanamkan begitu saja tanpa adanya return yang menjanjikan, sekurangnya apabila dana ditanamkan dalam bentuk akad mudharabah (walaupun tentunya menjadi kurang likuid) untuk keperluan lalu-lintas pembayaran. Dari sisi bank sendiri, tentu menganggarkan untuk pemberian bonus. Apabila hal tersebut terjadi secara rutin, berarti akan menjadikan kebiasaan menganggarkan pemberian bonus menjadi hal biasa dan lazim, nasabahnpun akan memahami, "mengharap" adanya bonus . Betapa tidak, dana yang ditanamkan begitu besar, apakah akan begitu saja digratiskan sementara bisnis "as usulan" adalah mobilisasi dana yang tentu ada biayanya. Lebih mendalam lagi, bonus sudah “diperjanjikan”walaupun secara lisan tentang besarnya bonus. Hal demikian yang perlu dicermati oleh para pengawas syariah baik dari DSN, DPS maupun masyarakat peduli syariah lainnya. Dalam bahasa syar'i-nya, sudah ada niat untuk mendapatkan bonus. Padahal tentunya mengcau pada inna a'malu biniyah (Segala sesuatunya bergantung pada niat). Dalam konteks produk giro wadiah, walaupun tidak ada bonus atau imbalan dalam akadnya(perjanjian awalnya), namun sudah ada niat/harapan untuk adanya bonus dikemudian hari. Inilah yang tipis perbedaanya antara syariah dan non syariahnya.

\section{Sertifikat Wadiah Bank Indonesia (SWBI)}

Sebagaimana disebutkan sebelumnya, SWBI adalah produk syariah yang dikeluarkan oleh Bank Indonesia (Bank Sentral Republik Indonesia). Bank Indonesia dapat menerima titipan atas ditempatkannya dana tersebut oleh masyarakat (perbankan syariah). Bank Indonesia dapat memberikan bonus, namun tidak diperjanjikan di awal perjanjian. Yang perlu dicermati antara lain :

i. Titipan ditetapkan dalam jangka waktu 1(satu) minggu, 2 (dua) minggu dan 1(satu) bulan. Padahal dalam prinsip syariahnya, dana titipan tersebut dapat diambil sewaktuwaktu dan ini hak dari si penitip dana. Bagi Bank Indonesia sebagai otoritas moneter, penetapan ini wajar karena apabila menyelaraskan pada Sertifikat Bank Indonesia (SBI) sebagai perangkat moneter, maka SWBI bisa dianggap sebagai perangkat moneter juga sehingga apabila tidak ada batasan waktu, maka fungsi sebagai perangkat moneternya menjadi sumir. Namun apabila dikaji dari sisi produk syariahnya memang menjadi sedikit kurang pas.

ii. Pada butir (2) pasal PBI No. 2/9/PBI/2000 tentang Sertifikat Wadiah Bank Indonesia memang ditetapkan "Dalam hal Bank Indonesia akan memberikan bonus kepada Bank atau UUS yang menitipkan dana", artinya bonus belum merupakan kepastian, sudah sesuai dengan syariah akad wadiah (titipan). Namun selanjutnya tertulis "maka besarnya bonus akan dihitung dengan menggunakan acuan tingkat indikasi imbalan Pasar Uang Antarbank berdas arkan prinsip Syariah (PUAS) yang merupakan rata -rata tertimbang tingkat indikasi imbalan Sertifikat Investasi Mudharabah Antarbank (Sertifikat IMA) yang terjadi di PUAS, pada tanggal penitipan dana. Tidakkah, kalimat tersebut sudah memberikan semacam "harapan yang mendekati pasti" bahwa bonus selalu akan diberikan kepada penitip dana. Terlebih lagi bahwa operasional SWBI sebagai perangkat moneter melibatkan uang milyaran rupiah, 
sebagaimana ditetapkan bahwa minimal dana yang dititipkan dalam bentuk SWBI sebesar Rp 500 juta dan diatas Rp500 juta dengan kelipatan Rp 50 juta penuh. Pertanyaan selanjutnya apakah bagi bank umum syariah yang menitipkan dana dalam jumlah besar akan begitu saja rela tanpa adanya income (pendapatan)? Sementara bank tersebut mengelola dana masyarakat agar mendatangkan return? Mengapa dana masyarakat tersebut tidak ditanamkan saja pada produk mudharabah, murabahah, ijaroh dan lain sebagainya yang sudah pasti mendatangkan return. Jawabnya tentu bahwa dana yang ditanamkan dalam bentuk SWBI juga mendatangkan return, hanya tidak diperjanjikan dimuka, namun dengan "harapan hampir pasti" bahwa pada saat SWBI jatuh tempo Bank Indonesia juga akan memberikan bonus. Maka disinilah tipisnya perbedaan antara "bonus sukarela" dan “bonus janji”. Dalam pandangan syariah tentu juga sudah dikenal makna dari hadits "Inna a'malu biniyah" (Sesungguhnya amal manusia tergantung pada niatnya". Apa tujuan/niat bank menanamkan dananya dalam bentuk SWBI, hanya menitipkan atau mengharapkan bonus? Niat tentu urusannya sama Alloh, bukan pada formalitas (bentuk formal perjanjian) atau perjanjian lisan antara mudi'(penitip dana) dan muda'(penerima titipan dana). Perlu dicermati bahwa kebiasaan tidak tertulis yang dilakukan berulang-ulang maka akan menjadi ikatan atau konvensi atau hukum. Pemberian bonus yang tidak diperjanjikan namun dilakukan berulang-ulang dan menjadi kebiasaan, lama-kelamaan akan menjadi keniscayaan.

3. Tabungan Wadiah
Tabungan adalah simpanan yang penarikannya hanya dapat dilakukan dengan syarat tertentu yang disepakati, tetapi tidak dapat ditarik dengan chek atau bilyet giro dan/atau alat lainnya yang dipersamakan dengan itu. Syarat tertentu itu misalnya penarikannya dibatasi dalam satu hari sekian rupiah. Dalam hal ini perlu dicermati pula azaz akad wadiah itu adalah titipan dana yang dapat diambil sewaktuwaktu, artinya terserah kepada mudi'(pemilik dana). Namun memang tergantung pada kesepakatan yang telah dibuat. Namanya titipan yang memang niatnya untuk dititipkan, bukan berniat untuk berinvestasi. Tidak ada bonus yang dijanjikan pada awalnya. Perlu dipahami oleh mudi' uang yang dititipkan dalam bentuk tabungan wadiah dalam kondisi :

$>$ Biasanya akan dikenakan biaya adminsitrasi, berarti uang akan berkurang

$>$ Nilai uang juga akan turun karena pasti terjadinya inflasi, biasanya sekurangkurangnya 5\%/tahun.

$>$ Tidak ada niat untuk investasi, uang semata-mata untuk dititipkan demi menjalankan syariah.

Pihak bank berkewajiban untuk menjelaskan kepada nasabah tentang arti/perbedan tabungan wadiah dengan tabungan mudharabah. Adakah nasabah yang menitipkan dananya kepada bank syariah dalam bentuk tabungan wadiah? Wallohu a'lam.

\section{KESIMPULAN DAN SARAN}

\section{A. KESIMPULAN}

1. Produk bank syariah dengan akad wadiah seperti Giro Wadiah di Bank Umum, Sertifikat Wadiah Bank Indonesia dan tabungan wadiah perlu lebih ditajamkan nilai-nilai kesyariahhnya dalam pelaksanaannya. 
2. Fatwa Dewan Syariah Nasional tentang produkproduk tersebut sudah cukup jelas, namun pengkajian tentang substansi produk perlu terus ditajamkan dalam tataran praksisnya.

3. Tentang persyaratan yang dikenakan pada produk tabungan wadiah, perlu dijelaskan agar tidak bertentangan dengan substansi produk bahwa dana titipan tersebut dapat diambil oleh penitipnya (penabung) sewaktu-waktu. Terlebih lagi, para penabung ini kebanyakan masyarakat kalangan bawah yang uangnya pas-pasan sehingga dalam penerapnnya produk perbanka syariah tetap memperhatikn kemaslahatan umat sebagaimana tujuan akhir, baik ekonomi maupun perbankan Islam adalah kemaslahatan umat.

\section{B. SARAN-SARAN}

1. Pihak-pihak yang terlibat dalam praktek perbankan syariah seperti Dewan Syariah Nasional, Dewan Pengawas Syariah dan masyarakat peduli perbankan syariah lain agar tidak hanya terpaku pada Fatwa-fatwa yang dikeluarkan oleh DSN, namun perlu mempelajari dan mendalami praktekpraktek perbankan di lapangan agar fatwafatwa dapat dijalankan selaras dengan praktek-praktek di lapangan.

2. Dunia perbankan begitu kompleks, menyangkut perekonomian, moneter, sistem pembayaran dan bahkan aspek sosiologis sehingga perlu kepakaran yang optimal agar praktek perbankan syariah menerapkan produk yang benar-benar syariah.

3. Masyarakat peduli perbankan syariah perlu proaktif dalam mengikuti perkembangan perbankan syariah. Dituntut bukan hanya harus memahami tentang prinsip syariah namun, pengetahuan perekonomiian secara luas.

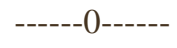

\section{DAFTAR PUSTAKA}

1. Bank Syariah, Teori, Kebijakan dan Studi Empiris di Indonesia

Oleh : DR Amir Mahmud dan H. Rukmana, SE, MSi

Penerbit Erlangga, Jakarta, 2010

2. Bank Syariah, Dari Teori dan Praktek

Oleh : DR M Safi'i Antonio. MEc

STEI, Tazkia, Jakarta

3. Bank Syariah, Wacana Ulama \& Cendekiawan Oleh : Muhammad Syafi'i Antonio

Penerbit : Tazkia Institut, Jakarta, 1999.

4. Perbankan Syariah

Oleh Lasmiatun, SE, MSi

Penerbit Kartini Press, Semarang, 2010

5. Tanya jawab Perbankan Syariah Oleh :Prof DR Abdul Ghofur Anshori, SH, MH

UII Press, Yogyakarta, 2010

6. Akad Bank Syariah Oleh : H.R. Daeng Naja

Penerbit Pustaka Yustisia, Yogyakarta, 2011

7. Bunga Bank Dalam Islam Oleh : DR Abu Sura'i Abdul Hadi MA

Guru Besar Syariah, Riyadh University, Saudi Arabia

Penerbit : Al Ikhlas, Surabaya, Indonesia, 1993.

8. Undang-Undang No. 21 tahun 2008 tentang Perbankan Syariah

9. Undang-Undang No. 7 tahun 1992 sebagaiman diubah dengan Undang-Undang No 10 tahun 1998 tentang Perbankan

10. Undang-Undang No 23 tahun 1999 sebagaimana diubah dengan Undang-Undang No 3 tahun 2004 tentang Bank Indonesia. 